\title{
Ethics in pediatric clinical research
}

\section{Opinion}

Children have been underserved in research and we notice that there are a kind of neglect and evasion by the physicians and clinicians of conducting the clinical research when the studied aspects are about children. This is due to several reasons such us some difficulties including the challenges of recruiting enough participants especially if it is a study on a rare disease and the cost which the firm will need in developing a new compound for a few number of people. ${ }^{1}$ Furthermore, the unwillingness of children to know and understand the risks related to the clinical study, so in such cases they cannot save their own rights in term of informed consent. The informed consent is a big problem the researchers are facing when they want to conduct a clinical trial involving children because it is difficult for the clinicians to make a child understand and have an idea about the clinical trials and its procedures or how it will undergo and what can be the outcomes of this research. Moreover, it is difficult to get the acceptance from the child himself under these circumstances. Additionally, the protective senses of parents and responsible make them not willing to register their children to join clinical researches. Therefore, we have a shortage of information concerning the reaction of the children to newly developed biodrugs and this makes the results somehow obscure. Also, even if a research is conducted, the clinicians cannot get a complete data due to the childrens inability of expressing what they feel after taking this new compound. For instance, a child of 3 or 4 years cannot even speak fluently, so it is a big problem for the research team to communicate with the child and ask him how does he feel after the clinical trial, this might explain why most pediatric therapies proceeds out of test and error. Several organizations and regulatory-agencies are working hard to make an end to this bad outcomes and risks by encouraging the biodrug firms, motivate them and persuade them to conduct pediatric clinical researches and studies and by specifying and creating policies and ethical guidelines that the researchers should adhere to. ${ }^{2}$ For example, the food and drug administration (FDA) and some ethics advisory committees have putted some regulations list regarding the safeguards and the protections from potential risks of scientific studies and clinical trials, the benefits that can be brought to the children include the potential of gaining knowledge about pediatric diseases and the chance to comprehend, secure, or relieve a bad problem that can give damage and effect the children health or welfare. ${ }^{3}$

In clinical researches including children, some ethical matters are more sensitive than in the clinical researches involving adults. Indeed, children need more safeguards and some special security because they do not have the ability to express themselves or their needs like adults. Moreover, for children and especially infants, their responds to the biodrug are completely different from the adults responds and a compound can be safe for the adults but in contrast give pain and grave consequences to the infant. That is why it is ethically required from the clinicians to guarantee additional awareness and attention to children to protect them. Also, researches on children should usually be accompanied by a longer follow-up than researches conducted on adults to determine whether the new biodrug have any long-term evolutional effects. Such supplemental adherence is very important
Volume 3 Issue I - 2018

\author{
Kadour Ghanemi,' Shuangsheng Yan ${ }^{1,2}$ \\ 'Department of Business Management, China Pharmaceutical \\ University, China \\ ${ }^{2}$ Department of Social Science, China Pharmaceutical University, \\ China
}

Correspondence: Shuangsheng Yan, Ph D, Associate Professor Director, The Philosophy of Teaching and Research Office, Department of Social Science, International Pharmaceutical Business School, China Pharmaceutical University, No 639, Longmian Avenue, Jiangning District, Nanjing, 211198 , China, Tel +8613305I 517 82, Email yss@cpu.edu.cn

Received: December 29, 2017| Published: February 08, 2018

and has a significant contribution in helping the promotion and increasing the quality of researches in pediatric fields. Conducting clinical researches on children is defined as a rational and moral duty founded on several ethical guidelines and standards. ${ }^{4,5}$ In fact, the organizations, regulations responsible of the human subjects protection and research teams should pay the maximum attention to these sensitive subjects (children). Sometimes, the ethical and regulatory safeguards for infant may prevent important clinical researches from being conducted on children and just done on adults. It is ethical that the research teams and the research sponsors and funders provide encouragement and guide all the participants in order to aid them realize their aims. Another ethical consideration can be required to respect the child decision regardless his age for example if the child refuses to participate or if the child is upset from the research procedures. The researchers should stop that procedure and let the child choose between continuing the tests or withdraw from it. In case the parents or the responsible of this child accepts that the child joins the study but the child refuses, the researchers should consider it as a refusal and exclude the child from the study. Moreover, the research staff should first concentrate on the emotional, psychological and cumulative outcomes related the child participation in the study because the children are very sensitive to such issues. The healthcare community is the second mother of the child, the sensitivity of the child needs a good awareness and consideration from the side of the healthcare system and research teams. Developing new pediatric biodrug which can improve children health and guarantee a good future is a high ethical behavior. However, the clinicians should concentrate on their clinical trials and the researches that give benefits to the children, and not just concentrating on doing business and enhancing the firm financial box via neglecting the ethical aspects. Nowadays the world is in dire need for new innovation of biodrugs, but this innovative biodrug should undergone an ethical way and manners, also it should cover the big and the young individuals in order to bring benefits to the whole community without exception and without any disadvantages and damage resulting from it. 


\section{Conflict of interest}

The authors declare that there is no conflict of interest.

\section{Acknowledgments}

We acknowledge the Jiangsu Overseas Research \& Training Program for University Prominent Young \& Middle-aged Teachers. Kadour Ghanemi is the recipient of a full scholarship from the China Scholarship council.

\section{References}

1. Gericke CA, Riesberg A, Busse R. Ethical issues in funding orphan drug research and development. $J$ Med Ethics. 2005;31(3):164-168.
2. Fernandez C. Ethical issues in health research in children. Canadian Paediatric Society (CPS). 2008;13(8):707-712.

3. Royal college of paediatrics and child health: Ethics advisory committee. guidelines for the ethical conduct of medical research involving children. Reprinted from Archives of Disease in Childhood. 2002;82 (2):177-182.

4. Neill SJ. Research with children: A critical review of the guidelines. $J$ Child Health Care. 2005;9(1):46-58.

5. Diekema DS. Conducting ethical research in pediatrics: A brief historical overview and review of pediatric regulations. J Pediatr. 2006;149(Suppl):S3-S11. 